\title{
Introduction: Framing 'Post-AIDS' and Global Health Discourses in 2015 and Beyond
}

\author{
Gráinne O'Connell ${ }^{1}$
}

Published online: 19 March 2017

(C) Springer Science+Business Media New York 2017

\begin{abstract}
This special issue, entitled 'Post-AIDS' and Global Health Discourses: Interdisciplinary Perspectives,' emerged from a one day Medical Humanities symposium at the Leeds Centre for Medical Humanities, at the University of Leeds, England, on February 27th 2015. This special issue focusses on the perceived deprioritising of HIV and AIDS in the Sustainable Development Goals, or SDGs, that were launched in 2015. The SDGs function as policy benchmarks for all entities within the United Nations system and they supersede the Millennium Development Goals, or MDGs, which expired in 2015. As the word millennium indicates, the MDGs were launched in 2000 and 2015 was designated as the benchmark year when the successes and shortcomings of the MDGs would be critically assessed. One key difference between the MDGs and the SDGs, which D'Ambruoso foregrounds (2013), is that the writing process underpinning the SDGs involved lengthy consultations, and feedback, with communities and health care practitioners around the world. By contrast, because the MDGs were mainly written by government officials, policy makers and health care practitioners without consulting wider communities, the processes underpinning the SDGs consultations are more inclusive than the MDGs. What is most critical about the SDGs for this special issue, however, is that they reflect a clear shift away from 'HIV exceptionalism' and towards what critics have described as 'post-AIDS' rhetoric, specifically when one compares the MDG health goal 6 and the SDG health goal 3.
\end{abstract}

Keywords 'Post-AIDS' · Global health $\cdot$ SDGs $\cdot$ HIV exceptionalism $\cdot$ Representation

This special issue, entitled 'Post-AIDS' and Global Health Discourses: Interdisciplinary Perspectives,' emerged from a one day Medical Humanities symposium at the Leeds Centre for Medical Humanities at the University of Leeds, England, on February 27, 2015. A central focus of the symposium, and this special issue, is the perceived deprioritising of HIV and

Gráinne O’Connell

gra_oconnell@hotmail.com

1 Core Faculty and Academic Coordinator at CIEE London - Global Institute, 46-47 Russell Square, London WC1B 4JP, UK 
AIDS in the seventeen Sustainable Development Goals, or SDGs, that were launched in 2015. The SDGs function as policy benchmarks for all entities within the United Nations system, and they supersede the eight Millennium Development Goals, or MDGs, which expired in 2015 (Background on the Goals 2017). As the word millennium indicates, the MDGs were launched in 2000, and 2015 was designated as the benchmark year when the successes and shortcomings of the MDGs would be critically assessed.

One key difference between the MDGs and the SDGs, which D'Ambruoso foregrounds (2013), is that the writing process underpinning the SDGs involved lengthy consultations and feedback with communities and health-care practitioners around the world. By contrast, because the MDGs were mainly written by government officials, policy makers and healthcare practitioners without consulting wider communities, the processes underpinning the SDGs consultations are more inclusive than the MDGs. Amina Mohammed, the Special Advisor to the UN on Post-2015 Development Planning, was directly involved in coordinating the consultation process for the SDGs, and she attests to the lack of a comparable process for the MDGs (Mohammed 2015; Rugg 2016).

What is most critical about the SDGs for this special issue, however, is that they reflect a clear shift away from 'HIV exceptionalism' and towards what critics have described as 'post-AIDS' rhetoric, specifically when one compares the MDG health goal 6 and the SDG health goal 3. 'HIV exceptionalism' is "the idea that the disease requires a response above and beyond 'normal' health interventions" (Smith and Whiteside 2010) and, unsurprisingly, whether or not 'HIV exceptionalism' is a necessity beyond 2015 has split critics: Some argue that the specificity of HIV stigma necessitates 'HIV exceptionalism' because of the need for individualised approaches to HIV treatment and prevention versus, by comparison, public health approaches to other communicable diseases (Fisher et al. 2009). By contrast, some demonstrate that 'HIV exceptionalism' retains currency but that 'HIV exceptionalism' has not been the "hegemonic" approach to HIV since 2006 (Oppenheimer 2009, 991). Furthermore, some argue that the impetus of the global rollout of HIV treatment and prevention programmes, since the early 2000s, has detracted from focussing on other diseases and conditions (Benton 2015) and that uncritical approaches to global health funding have prevented engaged and timely critiques with the political economy of HIV (Johnston et al. 2015).

Indeed, these last two critiques - of the impetus and political economy of the global rollout - are central to Mandisa Mbali's (2013) analysis of how global health funding is closely tied to geopolitics. For Mbali, in her study of how South African AIDS activists transformed global AIDS activism, the close link between geopolitics and global health funding necessitates critical scrutiny of global health provisos, especially the cuts and flat-lining of global health funding from 2007 onwards. Crucially, Mbali, like Jennifer Chan (2015), foregrounds that one of the milestones of AIDS activism across the world is that it catapulted human rights and community onto the global stage. However, Chan demonstrates that human rights discourses and community-led approaches have been co-opted by many neoliberal discourses and agendas to the extent that some NGOs or people are distanced from the communities they supposedly represent. In this sense, both Mbali's and Chan's critiques link to Michael April's argument (2010) for robust contextual analyses of why 'HIV exceptionalism' became a norm. More specifically, April argues for a careful reassessment of why the 1980s USA context necessitated 'HIV exceptionalism' especially because the global picture of HIV and AIDS has fundamentally changed since the 1980s: 
HIV exceptionalism was the common approach to testing in the early days of the epidemic in the United States of America (USA) during which the lack of treatment and threat of HIV-related stigma led to the prioritization of informed consent over case detection.

It needs to be made clear here that April stresses that a contextual approach to HIV is needed to understand 'HIV exceptionalism'. Thus, he is not blankly refusing 'HIV exceptionalism', but he is leaning away from individualised treatment and prevention approaches to HIV and AIDS given that the global picture of HIV has significantly changed.

Alongside the above reasons, there are two other major factors that have influenced the shift away from 'HIV exceptionalism' and towards 'post-AIDS' rhetoric: Firstly, the number of new HIV infections per year has steadily declined on a global scale since about 2003, and this fall has contributed to a paradigm shift in how AIDS is portrayed (UNAIDS 2014). Alan Whiteside summarises the shift by stating that "AIDS is no longer a discourse defining health emergency" though he proceeds to outline what are the contemporary challenges for combatting HIV and AIDS (2015, 459). Secondly, public health experts, particularly those coordinating within the UN and who contributed to the writing of the SDGs, have recognised the clear epidemiological shifts that have taken place on a global scale over the last thirty-five years: Non-communicable diseases, such as diabetes and cancer, are now as important across many global contexts as communicable diseases such as HIV, Tuberculosis and Malaria (UNAIDS 2014). Indeed, the recognition of non-communicable diseases is facilitated across the SDGs because of the cross-sectoral framework which is spliced by three core themes; reducing poverty, combatting gender inequality and recognising the challenges of every context's development agenda. Thus, the cross-sectoral framework actively reflects that health is connected to wider society rather than the historical pattern of designating health, particularly health budgets, as separate since at least the 1970s (Mohammed 2015).

However, while acknowledging the reasons underpinning the shift away from 'HIV exceptionalism', a central focus in this special issue are the contradictions that underpin 'post-AIDS' rhetoric in global health discourses such as the focus on the 'post-AIDS' future over the present: 'Post-AIDS' rhetoric is immediately noticeable in UNAIDS and WHO global health discourses such as UNAIDS press material since at least 2010 (UNAIDS 2010; UNAIDS 2016). PEPFAR, as a United States government initiative, also mirrors this rhetoric with its focus on an "AIDS free generation" in African contexts (PEPFAR 2012). Quite simply, the contradictions of 'post-AIDS' rhetoric is particularly glaring given that there is no functional cure for the HIV virus at present and, also, given the flattening of funding for treatment and prevention programmes, as noted by Mbali, since 2007.

Furthermore, as this special issue will demonstrate, there is an explicit need for interdisciplinary perspectives to HIV and AIDS in 2015 and beyond and not least given the move away from viewing HIV and AIDS as a crisis, since at least 2004. The need for such perspectives, as Alan Whiteside notes in a recent special issue of Review of African Political Economy on the political economy of HIV, is highly important because of the insularity that disciplinary specific approaches tend to replicate:

Further, [the authors in this special issue] emphasise the silo-based response to the epidemic, in which disciplinary boundaries limit the potential for the design of responses that are truly holistic, although it is emphasised that these boundaries work both ways, 
and that social scientists are also required to engage constructively with their biomedical colleagues. $(2015,336)$

Thus while staying attuned to the changing rhetoric of Global Health discourses, such as UNAIDS and the WHO, this special issue analyses the relevance, or possible critiques, of 'post-AIDS' rhetoric and global health discourses via interdisciplinary perspectives.

Crucially, all the articles in this issue demonstrate that 'post-AIDS' rhetoric has a history outside of global health organisations such as the WHO or UNAIDS, and the focus on the idea of a 'post-AIDS' future, for example, can be both hopeful and also empty: For Douglas Crimp, the idea of 'post-AIDS' begins to circulate in the early 1980s when queer subcultures in the global north made a distinction between the present and the past because of the transformative effect that AIDS had on queer lives, subcultures and histories including new distinctions between 'good' gays and 'bad' gays $(2002,9)$. For some, it is the post-1996 'Lazarus' moment when HAART became available to populations largely located in global north contexts though Brazil also offered HAART on its public health system in 1996. Monica Pearl describes the effect of HAART in 1996 as the "pharmaceutical threshold" in her literary analysis of AIDS representations in US novels $(2013,2)$. For others, it is 2003 onwards when global health discourses began to foreground the fall in the number of new HIV infections from UNAIDS surveillance data (Whiteside 2015).

Thus, all the articles acknowledge the juncture that 2015 represents, but the articles also foreground the continuing importance of stigma, the turn away from HIV and AIDS since at least the mid 2000s and the pressing necessity to foreground the role of inequality and the lack of political commitment to PrEP, or TasP, in Britain for example. Moreover, the spread of articles within this special issue reflects the Guest Editor's specific teaching and background research in literary, socio-historical and philosophical debates in Indian, Irish and South African contexts. Furthermore, the symposium, and thus this special issue, needed to address the very obvious transnational and global nature of AIDS histories especially the lack of explicit focus on south-south histories and analyses and, in the case of Ireland, the very small attention, to date, that has been dedicated to HIV and AIDS. However, the articles within this special issue all address one central question: Why are interdisciplinary approaches to 'post-AIDS' and global health needed in 2015 and beyond?

The opening article by Liz Walker examines how and why 'post-AIDS' discourse largely celebrates, what Walker calls, a biotechnical solution to HIV and AIDS over a complete roll out on a global stage. Her focus is primarily sub-Saharan African contexts in the global south, specifically South Africa, but Walker also compares the salient role that HIV stigma plays in both a global south context, such as South Africa, and a global north context such as Britain. Throughout, Walker argues that a truly holistic response to HIV and AIDS should acknowledge the exceptional nature of the history of HIV treatment and prevention and, above all, the embodied and social realities of living with HIV especially the complex effects that HIV stigma continues to play across both global north and global south contexts.

The second article, by Katherine Furman, analyses how the perceived tensions between mono-causal and multi-causal theories of disease aetiology underpinned AIDS denialism in South Africa during the late 1990s. Throughout, Furman utilises an analytical philosophy approach while staying attuned to Thabo Mbeki's role in AIDS denialism, especially how Mbeki's agreement with AIDS denialists can be 
linked to his belief in the importance of socio-economic factors over an account that embraces socio-economic alongside biological accounts.

The third essay, by Cormac O'Brien, analyses representations of HIV positive gay men in Irish theatre since the 1990s. While acknowledging the relatively small number of theatre productions that have addressed HIV positive gay men in an Irish context, O'Brien argues that homonormativity, as an expression of social acceptance in contemporary Ireland, has hijacked ideas of HIV positive gay men as complex protagonists in favour of a 'good gay/bad queer' distinction. 'Post-AIDS' culture, then, in O'Brien's paper simplifies the realities of living with HIV in contemporary Ireland, especially that HIV and AIDS is a part of queer life in Ireland in 2015.

The fourth essay, by Shamira Meghani, analyses contemporary representations of HIV in Indian literature and film. Throughout, Meghani foregrounds the gap between certain global north imaginaries and, also, the role of the modernity versus tradition axis. The latter, as Meghani proceeds to demonstrate, is not helpful, nor easy to reply to, given the complex imbrications of postcolonial history in India where the role of caste, and the social stigma attached to caste, is both normalised as central to these texts while representations of HIV Dalit subjects are inconceivable in mainstream representations.

The fifth essay, by Gráinne O'Connell, analyses HIV representations in Indian and South African literature and culture. While foregrounding the myriad pressures that are placed on both texts to represent HIV, the central focus of this article is the role of affective economies, personal testimonies and the need to continuously broaden HIV history, complicating any deterministic idea of temporality as progress. The essay concludes by revisiting the idea of the subaltern, via Gayatri Spivak, as O'Connell argues that HIV representations, even in light of the unfolding contradictions embedded in 'post-AIDS' rhetoric, need to be read and contextualised alongside increased rollout. Thus, this essay ends with the complex idea of self-representation, via nonfiction, and an embrace of interdisciplinary representations of HIV that do not offer that idea of what Berlant calls the fixed closure of symptomatic readings (2011).

The final paper, by Carla Tsampiras, analyses the historiography of AIDS histories via a South African historian's perspective working within the emerging Medical Humanities field in South Africa. Throughout, Tsampiras foregrounds the intense research focus on AIDS and AIDS histories particularly within biomedical circles and how AIDS histories need to be understood in relation to different ideas of temporality if we want a true global picture of what it means to write the history of AIDS. Most crucially, for Tsampiras, 'post-AIDS' discourses are fraught with tensions especially for a South African historian given that most AIDS research has tended to emerge from global north contexts and most of this research has been Biomedical and Social Science research. In conclusion, Tsampiras argues that AIDS histories in South Africa, and the broader global south, still need to be written and thus the idea of a 'post-AIDS' future does not yet ring true despite that the roll out of ART in South Africa is a milestone that should be acknowledged and celebrated.

In acknowledging the particular impact that HAART has had on the language of post-1996 global health discourses, this special issue unpacks the connotations of 'post-AIDS' in light of Cindy Patton's important critique that representations of HIV and AIDS, in both 'popular' and scientific forums, are always bound up with the role of science in wider society (2002). Overall, this special issue critiques the suggestions that HIV and AIDS may be 'over' as a global health issue because this 
idea is a statement of how certain groups wish to see HIV and AIDS represented rather than how HIV and AIDS are understood, debated and embodied.

Acknowledgements The editor would like to thank the anonymous reviewers for their helpful comments and Niamh O'Connell for her clear and patient editing skills.

\section{References}

April, Michael. 2010. "Rethinking HIV exceptionalism: The ethics of opt-out HIV testing in sub-Saharan Africa." Bulletin of the World Health Organisation. doi: 10.2471/BLT.09.073049.

Benton, Adia. 2016. HIV exceptionalism: Development through disease in Sierra Leone. Minneapolis: University of Minnesota Press.

Berlant, Lauren. 2011. Cruel Optimism. Durham: Duke University Press,

Crimp, Douglas. 2002. Melancholia and Moralism: Essays on AIDS and Queer Politics. Cambridge: MIT P.

D’Ambruoso, Lucia. 2013. "Global Health Post-2015: The Case for Universal Health Equity." Global Health Action 6 (1). doi:10.3402/gha.v6i0.19661.

Fisher, William A., Taylor Kohut and Jeffrey D., Fisher. 2009. “AIDS Exceptionalism: On the Social Psychology of HIV Prevention Research.” Social Issues and Policy Review 3:45-77.

Johnston, Deborah, Kevin Deane and Matteo Rizzo. 2015. "The Political Economy of HIV." Review of African Political Economy 42 (145): 335-341.

Mbali, Mandisa. 2013. South African AIDS Activism and Global Health Politics. London: Palgrave Macmillan.

Mohammed, Amina. 2015. "The New Universal Sustainable Development Goals for 2030: From Vision to Action." UCL Lancet Lecture, London, England, 12 November. https:/www.ucl.ac.uk/igh/news/previousevents-folder/2015lancetlecture.

Oppenheimer, Gerald M. 2009. "The Rise and Fall of AIDS Exceptionalism." American Medical Association Journal of Ethics 11:998-992.

Patton, Cindy. 2002. Globalizing AIDS. (Theory out of Bounds). Minneapolis: University of Minnesota Press.

Pearl, Monica. 2013. AIDS literature and Gay Identity: The Literature of Loss. London: Routledge.

Rugg, Deborah. 2016. "The Role of Evaluation at the UN and in the New Sustainable Development Goals: Towards the Future We Want." Global Policy 7:426-430.

Smith, Julia H and Alan Whiteside. 2010. "The History of AIDS Exceptionalism." Journal of the International AIDS Society. doi: 10.1186/1758-2652-13-47.

UNAIDS. 2010. UNAIDS Strategy 2011-2015 Getting to Zero. Accessed 10 September 2016. https://files. unaids.org/en/media/unaids/contentassets/documents/unaidspublication/2010/JC2034_UNAIDS_Strategy_ en.pdf.

UNAIDS. 2014. 90-90-90: An Ambitious Treatment Target to Help End the AIDS epidemic. Accessed 10 September 2016. http://www.unaids.org/en/resources/documents/2014/90-90-90.

UNAIDS. 2016. On the Fast-Track to an AIDS-Free Generation. Accessed 10 September 2016. http://www. unaids.org/en/resources/documents/2016/GlobalPlan2016.

United Nations Development Programme. 2017. "Background on the Goals." Accessed 5 January 2017. http://www.undp.org/content/undp/en/home/sustainable-development-goals/background.html.

United States President's Emergency Plan for AIDS Relief. 2012. PEPFAR Blueprint: Creating an AIDS-Free Generation. Accessed 10 September 2016. https://www.pepfar.gov/documents/organization/201386.pdf.

Whiteside, Alan. 2015. "The Key Questions in the AIDS Epidemic in 2015." Review of African Political Economy. doi:10.1080/03056244.2015.1064371. 